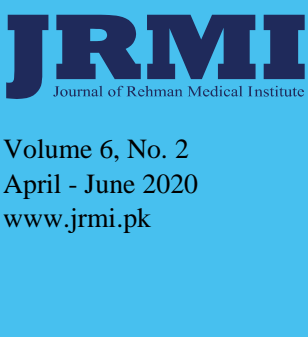

ORIGINAL ARTICLE

\title{
Comparison of growth indices in breast-fed and formula-fed infants and their correlation with zinc status
}

Mehwish Durrani, Muhammad Abubakar, Fearoz Khan, Mushyyada Durrani, Muhammad Shafiq

Submitted

May 21, 2020

Accepted

June 15,2020

Author Information

Dr. Mehwish Durrani Associate Professor Department of Biochemistry, Rehman Medical College, Peshawar, Khyber Pakhtunkhwa, Pakistan (Corresponding Author) Email:

mehwishdurrani@gmail.com

Dr. Muhammad Abubakar

Assistant Professor

Pak International Medical

College, Peshawar

Dr. Fearoz Khan

Senior lecturer Department of Biochemistry, Rehman

Medical College, Peshawar

Dr. Mushyyada Durrani Lecturer, Rehman College of Dentistry, Peshawar

Dr. Muhammad Shafiq Professor, Department of Biochemistry, Rehman Medical College, Peshawar

Citation: Durrani M, Abubakar M, Khan F, Durran M, Shafiq M. Comparison of growth indices in breast-fed and formula-fed infants and their correlation with zinc status. J Rehman Med Inst. 2020 Apr-Jun;6(2):12-6

\section{ABSTRACT}

Introduction: Zinc has many effects on human's multiple systems in the body, including gastrointestinal tract. It is essential for normal development, immune system and growth of an infant. Zinc deficiency increases the chances and severity of gastrointestina tract and respiratory infections. Children are at high risk of zinc deficiency as their requirements increases with growth. The amount of zinc absorbed from infant formulae is considerably lesser than that absorbed from mother's milk. The aim was to study the differences in the growth indices of breast-fed and formula-fed infants and also to look for the association of zinc, if any, with these indices.

Methodology: This cross-sectional study was performed from October 2017 to March 2018 in Peshawar, on 50 healthy infants $\{25$ breast-fed infants (BFI) and 25 formula-fed infants (FFI) \}. The infants' weight, height, BMI, head circumference and skinfolds (biceps and triceps) were recorded. Blood samples of all the infants were collected for zinc assay. Data were collected in an MS Excel sheet and descriptive data analysis was done by Minitab version 16 .

Results: It was observed that the head circumference (cm) of FFI was significantly higher $(40.32 \pm 2.34)$ in comparison to BFI $(38.12 \pm 4.46)$ whereas SDS weight, SDS BMI, biceps and triceps measurements did not reveal any significant difference in the two groups. The variables showing a significant positive correlation with zinc were age $(\mathrm{r}=0.328, \mathrm{p}=0.02)$ and SDS height $(\mathrm{r}=$ $0.274, p=0.05$ ) while SDS weight, SDS BMI, biceps and triceps measurements were not correlated with zinc status.

Conclusion: All the growth indices except head circumference of both breast-fed and formula-fed infants were comparable. Similarly, all these indices except SDS height were not associated with the levels of zinc during early infancy showing that zinc status does not affect the growth of infants at least in the early phase of life.

Keywords: Zinc, Growth indices, Breast-feeding, Formula feeding

The authors declared no conflict of interest. All author contributed substantially to the planning of research, data collection, data analysis, and write-up of the article, and agreed to be accountable for all aspects of the work.

\section{INTRODUCTION}

Mother and infant health are influenced by the dietary habits of breastfeeding females and impact the overall health conditions of an infant and mother. Malnutrition is one of the major causes of childhood mortality in early infancy. ${ }^{1-3}$ Infants up to the age of 6 months get most of their essential macronutrients (carbohydrates, proteins and lipids) from mother's milk in majority of cases. Recent literature revealed that oligosaccharides of breast milk, even non-nutritive, contribute to infant health and infant body composition in early years of life. For instance, levels of glucose and insulin in mother's milk are positive predictors for adiposity in infants who are born to non-diabetic mothers. $^{4}$

Body Mass Index (BMI) is a better indicator of infant body composition at age one month. Prompt weight gain during infancy has been related to childhood obesity. In 2006, WHO published BMI-for-age growth charts for children aged less than two years which are now obsolete for pediatric use. ${ }^{5}$ When growth indices (weight for age, length for age, and weight for length) of both formula-fed and breast-fed infants were compared, it was observed that in breast-fed infants at one, two and three month of life, these were significantly higher whereas in formula-fed infants only weight for age was significantly higher at one month interval up to 6 months. An Italian study showed that during first 12 months of life both formula-fed and breast-fed infants exhibit different growth patterns. ${ }^{6,7}$ Reported evidence suggest that breast feeding reduces risk of obesity in infants, but on the other hand there is research-based evidence pointing out that babies fed with mother's milk exhibit significant weight gain in first month and maintain it for the whole period of lactation, an aspect that has to be thoroughly investigated. ${ }^{8,9}$

Zinc is stored in the liver during intra uterine life which is sufficient for 4-6 months. Afterwards, it is supplied from daily diet; therefore at age six months, zinc becomes a nutritionally essential micro-nutrient. During this period, breast milk is considered to be a complete diet. According to WHO recommendation, breast milk is adequate 
for infants during first six months of life and continues along with appropriate weaning diet for initial two years of life. ${ }^{10,11}$

Metallothionein, a zinc-binding protein, is present in liver. The complex of metallothionein with zinc starts accumulating during the third trimester of pregnancy. At 4 months after birth, zinc levels become stable. ${ }^{12}$ Breast milk is the only source of zinc in infancy. Colostrum, the richest source of zinc for neonates, ${ }^{13,14}$ provides approx. $8 \mathrm{mg} / \mathrm{L}$ of zinc. This level starts declining and reaches up to $50 \%$ of the initial concentration within seven days. At age 2 months, it reduces further to $2 \mathrm{mg} / \mathrm{L}$, but this process is very slow as compared to first week of decline. At age one year, the infant is only able to extract $0.5 \mathrm{mg} / \mathrm{L}$ from mother's milk despite the increase in volume of breast milk with passage of time. ${ }^{13-15}$

Zinc storage in premature infants is very low as they have small livers and very short gastrointestinal tracts. Therefore, mothers require zinc supplementation for proper functioning of their body at the time of birth so as to avoid the complications of zinc deficiency. ${ }^{13,16}$ Eighty two percent of lactating or pregnant women have enough zinc intake. ${ }^{17}$ Zinc is said to be the first nutrient that starts limiting in breast milk, as its concentration is highest at commencement of lactation, then declines very rapidly during the initial three months. ${ }^{11}$ Keeping in view the significance of feeding modalities and role of zinc in infants, this study was designed to compare the growth indices between the feeding groups and their relationship with zinc level in early infancy.

\section{MATERIALS \& METHODS}

\section{Study design, ethics and sample size}

This was a cross-sectional study, carried out in Peshawar, Khyber Pakhtunkhwa from October 2017 to March 2018. The study was approved by the Khyber Medical University Ethics Board (KMU-Ethics Board). Based on median difference of $14.3 \mathrm{mmol} / \mathrm{kg}$ total short-chain fatty acids between breast fed and formula fed infants at 2 months of age from the study of Siigur et al $1993^{18}$ and considering margin of error of 5\%, total of 25 infants are required in each group (total $n=50$ ). Each participant was screened using a health check questionnaire to rule out any co-morbid conditions. Informed written consents were obtained from the mothers/guardian of the participants.

\section{Anthropometric assessment of infants}

Weight and length measurement of an infant was performed once. Infant crown-heel length was measured once by using headpiece and foot piece both applied perpendicular to the hard surface and non-stretch tape was used to measure the length in centimeters. Head circumference was measured at a level passing from supraorbital protuberance anteriorly and occipital protuberance posteriorly using non-stretch tape to the nearest $0.1 \mathrm{~cm}$. Each infant was weighed in Beurer digital baby scale (BY-80) in kilograms. Skin folds (biceps and triceps) were measured with the help of skinfold caliper (Holtain Ltd, Crosswell, UK). Height of the mothers was determined using a portable stadiometer with the head in horizontal Frankfort plane. Mid upper arm circumference was measured to the nearest $0.1 \mathrm{~cm}$ using a plastic measuring tape. Weight of the mother was taken by Beurer digital scale "GS 200 Allium" to the nearest $100 \mathrm{~g}$.

\section{Skinfold thickness measurement of enrolled subjects (infants and mothers)}

Skinfold thickness is used to measure total body fat and hence the distribution of fat to body mass. ${ }^{19}$ It measures the thickness of subcutaneous fat at various sites. The skinfold thickness of the enrolled participants was measured after informing the mothers about the skin fold measuring procedure. They were reassured by demonstrating the action of the caliper on their index figure that there will be no pain and the infant will feel a little discomfort. The biceps and triceps skin folds of both the formula-fed infants as well as breast-fed infant along with their mothers were measured. "Holtain skin-fold caliper (Holtain Ltd, Croswell, UK)" was used for this purpose. Skin fold thickness was measured at the nearest $0.1 \mathrm{~mm}$.

\section{Triceps skin fold}

The participant skin was firmly clenched with index finger and thumb in order to hold the two thickness layers of skin and subcutaneous fat but not the muscles. The caliper was then placed over the skinfold with 90-degree angle. The caliper was held for five seconds and the reading was noted.

\section{Biceps skin fold}

For measuring the biceps, upper arm midline anteriorly, $1 \mathrm{~cm}$ above the mark used for triceps reading was taken by the caliper.

\section{Collection of blood samples, plasma zinc extraction and analysis}

Blood samples of infants and their mothers were collected in Li-heparinized tubes (Yaohua Medical). Plasma was separated and stored at $-80^{\circ} \mathrm{C}$ until analysis. All the glassware was soaked in $10 \% \mathrm{HNO}_{3}$ for $24 \mathrm{hrs}$, then rinsed three times with deionized water. Hemolyzed samples were excluded; $0.4 \mathrm{ml}$ of plasma sample and $3 \mathrm{ml}$ of Nitric acid (65\%) were added into a $25 \mathrm{ml}$ beaker and digested at $70-80^{\circ} \mathrm{C}$ on an electric hot plate for 90 minutes. Thereafter, $1.5 \mathrm{ml}$ of hydrogen peroxide $(30 \%)$ was added into the beaker and the digestion was continued. When the remaining volume was reduced to about $0.5-1 \mathrm{ml}$, the liquid was transferred into a $5.0 \mathrm{ml}$ volumetric flask after cooling, followed by the addition of nitric acid stock standard solution to obtain a final volume of $5 \mathrm{ml}$. Samples were then taken for zinc analysis to the Center of Research laboratory at Peshawar University. Atomic absorption Spectrophotometry technique was used for zinc assay.

\section{Statistics}

All data collected during the study span were arranged and organized on Excel sheet. Anthropometric data were then copied to statistical tool Minitab version $16{ }^{\circledR}$ for descriptive statistics. Normality of data was assessed by Anderson-Darling test for continuous variables like SDS height, SDS weight, SDS BMI and BMI. Probability plots signified that anthropometric data were normally distributed hence parametric statistics were applied. Data were expressed as mean $\pm \mathrm{SD}$; p values $\leq 0.05$ were considered significant. 


\section{RESULTS}

Demographic and anthropometric data consisted of family size, number of siblings, age of infant at the time of assessment, SDS height, SDS weight and SDS BMI (Table1); Two-sample T-test was applied to calculate $\mathrm{p}$ value.

Table 1: Anthropometric and demographic characteristics of infa
\begin{tabular}{|l|c|c|}
\hline \multicolumn{1}{|c|}{ Variables } & Mean & SD \\
\hline Height $(\mathrm{cm})$ & 53.42 & 5.84 \\
\hline Weight $(\mathrm{kg})$ & 5.37 & 1.01 \\
\hline SDS Height & -2.75 & 3.10 \\
\hline SDS Weight & -0.53 & 2.05 \\
\hline BMI (kg/m2) & 19.17 & 4.11 \\
\hline SDS BMI & 1.59 & 2.30 \\
\hline Age at Assessment (days) & 78.40 & 35.88 \\
\hline Family Size (n) & 6.78 & 3.30 \\
\hline No. of siblings (n) & 2.00 & 2.07 \\
\hline
\end{tabular}

Plasma zinc levels $(\mathrm{mg} / \mathrm{L})$ in breast-fed group were $0.185 \pm$ 0.219 (mothers) and $0.138 \pm 0.118$ (infants) while in formulafed group the levels were $0.091 \pm 0.010$ (mothers) and $0.120 \pm$ 0.026 (infants). The zinc levels were comparable in the infants of both groups whereas, the level was significantly higher $(\mathrm{p}=0.045)$ in the mothers of breast-fed group as compared to formula-fed group (Table 2).

Table 2: Plasma zinc status of mothers and infants

\begin{tabular}{|l|c|c|c|c|c|c|}
\hline \multirow{2}{*}{ Variables } & \multirow{2}{*}{$\begin{array}{c}\text { Normal } \\
\text { reference } \\
\text { levels mg/L }\end{array}$} & \multicolumn{2}{l}{ Breast-fed infants } & \multicolumn{2}{l|}{ Formula-fed infants } & \multirow{2}{*}{ p value } \\
\cline { 3 - 6 } & Mean & SD & Mean & SD & \\
\hline $\begin{array}{l}\text { Plasma zinc of } \\
\text { mothers' mg/L }\end{array}$ & $0.66-1.10$ & 0.185 & 0.219 & 0.091 & 0.0100 & $0.045^{\dagger}$ \\
\hline $\begin{array}{l}\text { Plasma zinc of } \\
\text { infants' mg/L }\end{array}$ & $0.60-1.20$ & 0.138 & 0.118 & 0.120 & 0.026 & 0.482 \\
\hline
\end{tabular}

Individual anthropometric parameters between the two groups formulanfedshow any significant difference. However, it was noted that the head infants (FFI) and breast-fed infants (BFI) were evaluated using pairecirteumference of FFI was significantly higher (40.32 \pm 2.34$)$ as compared test. The mean anthropometric measurements between the two groupstdiBFI $(38.12 \pm 4.46)$, $p<0.05$ (Table 3$)$.

Table 3: Mean differences in anthropometric parameters between the groups

\begin{tabular}{|c|c|c|c|c|c|}
\hline \multirow{2}{*}{ Variables } & \multicolumn{2}{|c|}{ Breast-fed infants } & \multicolumn{2}{|c|}{ Formula-fed infants } & \multirow{2}{*}{ P-value } \\
\hline & Mean & SD & Mean & SD & \\
\hline Head Circumference $(\mathrm{cm})$ & 38.12 & 4.46 & 40.30 & 2.36 & $0.03^{\dagger}$ \\
\hline Biceps (mm) & 0.14 & 0.05 & 0.14 & 0.05 & 0.78 \\
\hline Triceps (mm) & 0.15 & 0.06 & 0.14 & 0.05 & 0.63 \\
\hline BMI SDS & 1.25 & 2.41 & 1.94 & 2.19 & 0.29 \\
\hline SDS height $(\mathrm{cm})$ & -0.65 & 3.67 & -0.86 & 2.49 & 0.81 \\
\hline SDS weight $(\mathrm{kg})$ & -0.76 & 2.49 & -0.31 & 1.53 & 0.44 \\
\hline
\end{tabular}

Correlation of anthropometric and demographic variables with plasma zinc of infants

Pearson correlation was applied to assess the correlation of infants' zinc with age, number of siblings, family size, BMI SDS and SDS height and SDS weight. Variables showing significant positive correlation were age $(\mathrm{r}=0.328, \mathrm{p}=0.021)$ and SDS height $(\mathrm{r}=0.274, \mathrm{p}=0.056)$. All other variables like number of siblings ( $\mathrm{r}=-0.050, \mathrm{p}=0.425)$, family size $(\mathrm{r}=-0.117, \mathrm{p}=0.735)$ and BMI SDS $(\mathrm{r}=-0.222, \mathrm{p}=0.125)$ showed negative but insignificant correlation (Table 4). 
Table 4: Correlation of plasma zinc of infants with anthropometric and demographic variables

\begin{tabular}{|l|c|c|}
\hline \multicolumn{1}{|c|}{ Variables } & Pearson correlation & p value \\
\hline Age (days) & 0.32 & $0.02^{\dagger}$ \\
\hline No of siblings & -0.05 & 0.42 \\
\hline Family Size (n) & -0.11 & 0.42 \\
\hline SDS BMI & -0.22 & 0.12 \\
\hline SDS height & 0.27 & $0.05^{\dagger}$ \\
\hline Biceps & 0.23 & 0.11 \\
\hline Triceps & 0.17 & 0.22 \\
\hline \multicolumn{2}{|c|}{ Significant $p$ value $\left.{ }^{+} P<0.05,{ }^{*} P=<0.01,{ }^{\dagger+} P<0.0001\right)$} \\
\hline
\end{tabular}

\section{DISCUSSION}

It is well established that the breastfeeding is an excellent source of nutrients for the infants..$^{20,21}$ It is considered and recommended the "only" source of nutrition in the early six months of infancy. It has been reported that human milk has the ability to protect infants against excessive weight gain and later on obesity in adulthood. Our findings in this study support the later notion, as we found that the mean BMI SDS in breast-fed infants was lower than the formula-fed infants, but the difference could not attain the level of significance $(\mathrm{p}=0.295)$. Traditional formula milk contains higher contents of protein than breast milk. ${ }^{8}$ Protein-rich formulae are known to enhance plasma insulin levels which, in turn, lead to release of insulin-like growth factor-1 and may lead to weight gain initially and later obesity in the adulthood. ${ }^{8,22}$ Contrary to this, some studies have reported that the in formulafed infants the mean SDS weight were lower as compared to breast-fed infants, the observation attributed the authors to the prevalence of diarrhoea in the formula infants. ${ }^{3}$

Recent studies support that the human milk contains more contents of non-nutritive carbohydrates like human milk oligosaccharides (HMOs) which can potentially contribute to body composition and infants' growth. This interesting area requires further investigations which may help to identify the potential contributors of infant's growth and body mass composition during early and late infancy., ${ }^{4,23}$ The means of SDS height when compared between the breast fed and formula fed infants didn't show any major differences. Interestingly, the formula-fed infants increase in mean length was higher than breast fed infants endorsing the findings of earlier reports. ${ }^{24-26}$

The mean measurement of the head circumference was significantly higher in formula-fed infants when compared to breast-fed infants. This was in contrast to the observation in a study conducted by Michaelsen KF et al ${ }^{27}$ who didn't find any differences in the mean measurement of both the groups this might be due to fact that their study population was older than the infants included in our study. The indices of adiposity like biceps and triceps skin fold measurement in our study did not vary significantly between the groups as has been reported previously by various authors..$^{28,29}$ However, Salmenpera L et al ${ }^{30}$ have reported that adiposity indices were relatively higher in formula-fed infants than breast-fed infants which they attributed to the early weaning in addition to the formula milk.

Analysis of the plasma zinc levels showed inverse significant correlation with age of infants and agree with the observations of Okolo SN et al. ${ }^{31}$ We also explored the relationship of infant zinc with the growth rate of infants. No significant correlation was observed with the weight, height SDS, and adiposity indices. Similar observations have been reported by Salmenperä $\mathrm{L}$ et $\mathrm{al}^{32}$ These findings indicate that low zinc levels may not influence the aforementioned parameters.

\section{CONCLUSION}

All the growth indices except head circumference of both breast-fed and formula-fed infants were not significantly different revealing a comparable effect of the two modes of feeding on infant growth. Similarly, all these indices except SDS height were not associated with the levels of zinc during early infancy showing that zinc status does not affect the growth of infants at least in the early phase of life

\section{REFERENCES}

1. Moradi M, Maracy MR, Esmaillzadeh A, Surkan PJ, Azadbakht L. Associations Between Dietary Energy Density in Mothers and Growth of Breastfeeding Infants During the First 4 Months of Life. J Am Coll Nutr. 2018;37(8):731-7.

2. Bhutta ZA, Berkley JA, Bandsma RH, Kerac M, Trehan I, Briend A. Severe childhood malnutrition. Nature Reviews Disease Primers. 2017;3(1):1-18.

3. Chauhan MG, Mehta DP, Koria B, Patel $\mathrm{H}$, Singh M. Assessment of weight gain pattern of exclusively breastfed and nonexclusively breastfed infants in Bhavnagar city, Gujarat. Int J Med Sci Public Health. 2016;5(01):64.

4. Goran M, Martin A, Alderete T, Fujiwara $\mathrm{H}$, Fields D. Fructose in breast milk is positively associated with infant body composition at 6 months of age. Nutrients. 2017;9(2):146.

5. Roy SM, Fields DA, Mitchell JA, Hawkes CP, Kelly A, Wu GD, et al. Body mass index is a better indicator of body composition than weight-for-length at age 1 month. J Pediatr. 2019;204:77-83. e1

6. Agostoni C, Grandi F, Gianni M, Silano M, Torcoletti $\mathrm{M}$, Giovannini $\mathrm{M}$, et al. Growth patterns of breast fed and formula fed infants in the first 12 months of life: an Italian study. Arch Dis Child. 1999;81(5):395-9.

7. Rzehak P, Oddy WH, Mearin ML, Grote V, Mori TA, Szajewska H, et al. Infant feeding and growth trajectory patterns in childhood and body composition in young 
adulthood. Am J Clin Nutr. 2017;106(2):568-80.

8. Saure C, Armeno M, Barcala C, Giudici V, Mazza CS. Excessive weight gain in exclusively breast-fed infants. J Pediatr Endocrinol Metabol. 2017;30(7):719-24.

9. Kalies H, Heinrich J, Borte N, Schaaf B, Von Berg A, Von Kries R, et al. The effect of breastfeeding on weight gain in infants: results of a birth cohort study. Eur J Med Res. 2005;10(1):36-42.

10. Lazzerini M. Oral zinc provision in acute diarrhea. Curr Opin Clin Nutr Metab Care. 2016;19(3):239-43.

11. Dumrongwongsiri O, Suthutvoravut U, Chatvutinun S, Phoonlabdacha P, Sangcakul A, Siripinyanond A, et al. Maternal zinc status is associated with breast milk zinc concentration and zinc status in breastfed infants aged 4-6 months. Asia Pacific J Clin Nutr. 2015;24(2):27380.

12. Ackland ML, Michalczyk AA. Zinc and infant nutrition. Arch Biochem Biophys. 2016;611:51-7.

13. Krebs NF. Zinc transfer to the breastfed infant. Journal of Mammary Gland Biology and Neoplasia. 1999;4(3):259-68.

14. Doneray H, Olcaysu E, Yildirim A, Ozden A. The effect of the zinc concentration in breast milk on neonatal weight gain. J Trace Elem Med Biol. 2017;41:32-5.

15. Prasad AS. Zinc deficiency in women, infants and children. J Am Coll Nutr. 1996;15(2):113-20.

16. Griffin IJ, Domellöf M, Bhatia J, Anderson DM, Kler N. Zinc and copper requirements in preterm infants: an examination of the current literature. Early Hum Dev. 2013;89:S29-S34.
17. Taylor AJ, Jones LJ, Osborn DA. Zinc supplementation of parenteral nutrition in newborn infants. Cochrane Database of Systematic Reviews. 2017(2).

18. Siigur U, Ormisson A Tamm A.. Faecal short-chain fatty acids in breast-fed and bottle-fed infants. Acta Paediatrica. 1993;82(6-7):536-8.

19. Wells JCK, Fewtrell MS. Measuring body composition. Arch Dis Child. 2006;91(7):612-7.

20. Harmsen HJ, Wildeboer-Veloo AC, Raangs GC, Wagendorp AA, Klijn N, Bindels JG, et al. Analysis of intestinal flora development in breast-fed and formula-fed infants by using molecular identification and detection methods. J Pediatr Gastroenterol Nutri. 2000;30(1):61-7.

21. Liu Z, Roy NC, Guo Y, Jia H, Ryan L, Samuelsson L, et al. Human breast milk and infant formulas differentially modify the intestinal microbiota in human infants and host physiology in rats. J Nutr. 2015;146(2):191-9.

22. Dutta S, Hazarika RD, Banerjee S, Anwar F, Rao S. Protein quality in early infancy and long-term health outcomes. Clin Epidemiol Global Health. 2017;5(3):101-6.

23. Ukegbu A, Ebenebe E, Ukegbu P. Breastfeeding pattern, anthropometry and health status of infants attending child welfare clinics of a teaching hospital in Nigeria. South Afr J Clin Nutr. 2010;23(4):191-6.

24. Roche AF, Guo S, Siervogel RM, Khamis HJ, Chandra RK. Growth comparison of breast-fed and formula-fed infants. Can J Public Health. 1993;84(2):132-5.
25. Dewey KG, Heinig MJ, Nommsen LA, Peerson JM, Lonnerdal B. Growth of breast-fed and formula-fed infants from 0 to 18 months: the DARLING Study. Pediatrics. 1992;89(6 Pt 1):1035-41.

26. Wood CT, Skinner AC, Yin HS, Rothman RL, Sanders LM, Delamater AM, et al. Bottle size and weight gain in formula-fed infants. Pediatrics. 2016;138(1).

27. Michaelsen KF, Petersen S, Greisen G, Thomsen BL. Weight, length, head circumference, and growth velocity in a longitudinal study of Danish infants. Dan Medl Bull. 1994;41(5):577-85.

28. Innis SM, Auestad N, Siegman JS. Blood lipid docosahexaenoic and arachidonic acid in term gestation infants fed formulas with high docosahexaenoic acid, low eicosapentaenoic acid fish oil. Lipids. 1996;31(6):617-25.

29. Ziegler EE. Growth of breast-fed and formula-fed infants. Nestle Nutrition workshop series Paediatric Programme. 2006;58:51-9; discussion 9-63.

30. Salmenpera L, Perheentupa J, Siimes MA. Exclusively breast-fed healthy infants grow slower than reference infants. Pediatr Res. 1985;19(3):307-12.

31. Okolo SN, Onwuanaku C, Okonji M, VanderJagt DJ, Millson M, Churchwell C, et al. Concentration of eight trace minerals in milk and sera of mother-infant pairs in northern Nigeria. J Trop Pediatr. 2000;46(3):160-2.

32. Salmenperä L, Perheentupa $J$, Näntö $V$, Siimes MA. Low zinc intake during exclusive breast-feeding does not impair growth. J Pediatr Gastroenterol Nutr. 1994;18(3):361-70. 